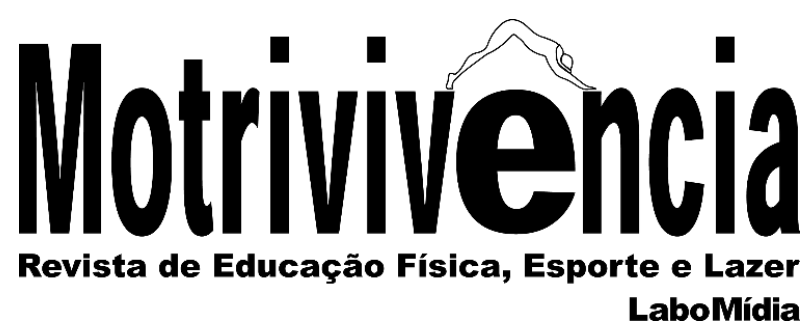

\title{
Competição e violência simbólica em jogos online: reflexões a partir do World of Warcraft
}

\section{RESUMO}

Dentre as modalidades de jogos digitais têm crescido os chamados jogos online multiplayers, jogos nos quais vários jogadores competem, interagem e socializam mesmo estando distantes geograficamente. O presente texto é um recorte de pesquisa de caráter etnográfico que utilizou o World of Warcraft e seu mundo virtual como campo de estudo. Buscou-se, a partir de aproximações e analogias com as práticas esportivas, problematizar atividades específicas realizada no universo virtual do jogo, mais relacionadas à competição. Destacou-se questões relacionadas à violência simbólica, à racionalização e à quantificação do desempenho. Percebeu-se que as relações estabelecidas no universo do jogo não são necessariamente harmônicas e nem sempre a interação se dá de forma amistosa, cordial ou pacífica. Cobranças acintosas, xingamentos e comentários depreciativos foram frequentemente observados.

PALAVRAS-CHAVE: Conflito; Violência simbólica; Competição; Jogos digitais; Jogos eletrônicos

\section{Leoncio José de Almeida Reis}

Doutorado em Educação Física Universidade Federal do Paraná, Câmara de Licenciatura em Educação Física, Matinhos, Brasil leojar_edf@email.br

'Dhttps://orcid.org/0000-0002-4365-0674

\section{Fernando Renato Cavichiolli}

Doutorado em Educação Universidade Federal do Paraná, Departamento de Educação Física, Curitiba, Brasil cavicca@hotmail.com ${ }^{\circ}$ https://orcid.org/0000-0001-8925-2420 


\title{
Competition and simbolic violence in online games: reflections from World of Warcraft
}

\begin{abstract}
Among the modalities of digital games, the so-called multiplayer online games have grown, games in which several players compete, interact and socialize even if they are geographically distant. This paper is an excerpt from an ethnographic research that used one of these games, World of Warcraft, as a field of study. Based on approximations and analogies with sports practices, an attempt was made to problematize specific activities carried out in the virtual universe of the game, more related to competition. Issues related to symbolic violence, rationalization and quantification of performance were highlighted. It was noticed that public relations in the game universe are not necessarily harmful and that interaction is not always friendly, cordial or peaceful. Disgusting demands, name-calling and derogatory comments were frequently observed.
\end{abstract}

KEYWORDS: Conflict; Symbolic violence; Competition; Games; Digital games

\section{Competencia y violencia simbólica en juegos online: reflexiones de World of Warcraft}

\section{RESUMEN}

Entre las modalidades de los juegos digitales han crecido los llamados juegos online multijugador, juegos en los que varios jugadores compiten, interactúan y socializan aunque estén geográficamente distantes. Este artículo es un extracto de una investigación etnográfica que utilizó uno de estos juegos, World of Warcraft, como campo de estudio. A partir de aproximaciones y analogías con las prácticas deportivas, se intentó problematizar actividades específicas que se realizan en el universo virtual del juego, más relacionadas con la competición. Se destacaron cuestiones relacionadas con la violencia simbólica, la racionalización y la cuantificación del desempeño. Se notó que las relaciones públicas en el universo del juego no son necesariamente dañinas y que la interacción no siempre es amistosa, cordial o pacífica. Con frecuencia se observaron demandas repugnantes, insultos y comentarios despectivos

PALABRAS-CLAVE: Conflicto; Violencia simbólica; Competencia; Juegos electrónicos; Juegos digitales; 


\section{INTRODUÇÃO}

Dentre as modalidades de jogos digitais $^{1}$ existentes no mercado têm crescido aquela nas quais vários jogadores interagem entre si mesmo estando distantes geograficamente. São os chamados jogos online ou jogos multiplayers (multijogadores).

Se antes os jogos digitais eram jogados simultaneamente por no máximo duas pessoas, que ainda necessitavam dividir o mesmo ambiente físico e o mesmo aparelho, com os avanços tecnológicos e com a popularização da internet em alta velocidade inovações conceituais nos jogos levaram a criação de espaços sociais virtuais nos quais pessoas culturalmente diferentes e geograficamente distantes passaram a interagir, se relacionar e sociabilizar.

Tal como em outras atividades de lazer e esportivas, é possível e esperado que nos espaços virtuais desses jogos os sujeitos acabem, querendo ou não, interagindo: conversam, brincam, discutem, trocam ofensas, fazem amizades e inimizades, formam grupos, compartilham ideias, tecem intrigas, fofocam, trocam ameaças, criam rixas, vangloriam suas conquistas, disputam prestígio e poder, etc.

Porém, diferente das redes sociais estabelecidas a partir do contato face-a-face e da presença física, nos ambientes virtuais dos jogos não há contato corporal e nem, na maioria das vezes, contato visual. Resguardados pelo anonimato e pelo isolamento espacial (e temporal) sujeitosjogadores trocam todo tipo de afeto e desafeto com quem não veem nem alcançam, e com quem não pode vê-los nem os alcançar.

O presente texto é um recorte de pesquisa de caráter etnográfico que utilizou o jogo World of Warcraft e seu mundo virtual como campo de estudo (REIS, 2013). Intenta-se, a partir de aproximações e analogias com as práticas esportivas, problematizar atividades específicas realizada no universo virtual do jogo - as chamadas raides. Destaca-se questões relacionadas à violência simbólica, à racionalização e à quantificação do desempenho.

\footnotetext{
${ }^{1}$ Jogos digitais (ou jogos eletrônicos) já não são novidades como objetos de estudo e de intervenção dentro da área da Educação Física. Inclusive, no que se refere ao currículo escolar da educação básica, figuram como objetos de conhecimento dentro da unidade temática Jogos e Brincadeiras na Base Nacional Comum Curricular.
} 


\section{RAIDES: PERFORMANCE E COMPETIÇÃO}

Raide é uma atividade do World of Warcraft (abreviado por WOW) envolvendo 10 ou 25 jogadores que, juntos, atuando sincronizada e organizadamente, tentam completar desafios do jogo derrotando inimigos controlados pelo computador.

Os jogadores que compõem o grupo são escolhidos de acordo com suas funções e especialidades dentro do jogo, de modo a formar uma equipe completa, balanceada e autossuficiente. Juntos, formam o equivalente a uma equipe esportiva, com cada jogador ocupando uma posição pré-definida e cumprindo um papel específico no time².

Geralmente essas atividades são organizadas em dias e horários combinados de acordo com a disponibilidade dos membros (ex.: toda terça e quinta das $20 \mathrm{~h}$ às $22 \mathrm{~h}$ ), mas como nem sempre é possível constituir um grupo fixo, é comum a convocação às pressas de substitutos (entre as centenas de desconhecidos online) para completar a equipe ${ }^{3}$.

Para que um grupo de jogadores consiga êxito na realização dessa atividade, é necessária uma série de acordos e procedimentos: os jogadores precisam se comunicar oralmente (utilizando softwares de comunicação por voz); preferencialmente devem estar entrosados e acostumados a jogar juntos; devem "saber a luta", ou seja, ter os conhecimentos necessários sobre como agir e proceder durante o combate; precisam conhecer as características de seu personagem tendo coordenação motora e rapidez suficientes para acionar suas habilidades a tempo (utilizando mouse e teclado); e, por fim, necessitam “equipar” seu personagem da maneira mais eficiente possível.

Misturam-se aí saberes de ordem conceitual, adquiridos por meio de busca e estudo nos diversos canais e plataformas online construídos pela própria comunidade de jogadores e saberes de ordem tática (tal como nos esportes com interação ${ }^{4}$ ), adquiridos por meio do exercício contínuo do jogar.

A dificuldade de realização das raides cria uma atmosfera tensa, excitante e altamente competitiva; um ambiente perfeito para atuações performáticas; um espaço social propício à

\footnotetext{
${ }^{2} \mathrm{Na}$ linguagem nativa usa-se a palavra inglesa core (que significa núcleo em português).

${ }^{3}$ Tal como na prática esportiva, quando se tenta preencher uma lacuna no time com convites do tipo: "falta um!" ou "precisamos de um goleiro!", direcionados a observadores e/ou desconhecidos externos a partida.

${ }^{4}$ Empresto o conceito da proposta pedagógica de Gonzales e Fraga (2012) e Gonzales e Bracht (2012) aplicada no âmbito da Educação Física e do ensino dos esportes. Diferente dos esportes sem interação com relação ao adversário, os esportes com interação exigem permanentes e constantes "tomada de decisão" dos jogadores em virtude de sua dinâmica essencialmente tática. Arrisco-me a utilizar esse entendimento para discutir uma prática a princípio nãoesportiva (os jogos digitais) por entender que, a não ser pela dimensão e amplitude do gesto motor (um chute contra um apertar de botão, por exemplo) não há diferença significativa em termos conceituais no "mecanismo de processamento de informação" em si.
} 
exaltação dos sentidos e das emoções - no sentido construído por Elias e Dunning (1992) sobre as práticas de lazer. Talvez derive daí o seu sucesso enquanto atividade dentro do jogo.

Lembra a antropóloga Nardi (2010), ao realizar estudo etnográfico também no WOW, que, nas raides, devido a sua complexidade, o menor erro pode por tudo a perder, assim como uma pequena vantagem pode levar a uma vitória "suada". Um movimento errado, uns segundos de distração, uma habilidade usada tardiamente, um aperto indevido de uma tecla, qualquer mínimo deslize pode levar o grupo inteiro à derrota. A tensão é ainda maior porque os erros, os descuidos e as falhas são imediatamente percebidos e quem os cometeu prontamente identificados.

Ao contrário de parte dos jogos e atividades esportivas coletivas, cujo erro pode ser uma constante (ex.: rebatidas na rede no tênis); não ser tão decisivo (no vôlei o erro geralmente concede ponto para o adversário mas não necessariamente decreta a derrota); ou ainda não ser tão evidente e passar despercebido ou percebido apenas por aqueles que estão mais próximos (ex.: um mal posicionamento no futebol); nas atividades de raide o erro, o descuido, por mais simples que seja (deixar de apertar um botão numa circunstância específica, por exemplo), pode resultar numa derrota coletiva.

Além disso, diferente das atividades esportivas em que a cobrança pode ser individualizada (de um jogador para com o outro) ou ser ouvida somente por quem está na proximidade, nas raides a cobrança, a chamada de atenção, o "puxão de orelha" é em geral simultaneamente ouvido por todos no sistema de voz ou visto por todos no canal de bate-papo coletivo.

O fato é que essa forma de organização particular contribui para a tensão e eventuais conflitos eclodidos no âmbito do jogo. Participei de atividades de raides em que jogadores ficavam incomodados com o erro alheio e reiteravam pedidos de mais atenção, mais concentração. Outros, mais impacientes, manifestavam em alto e bom som sua irritação. Cheguei a registrar comentários austeros e até xingamentos. Situações mais extremas, mas nem de longe incomuns, terminam em episódios de violência simbólica ${ }^{5}$.

Jogadores reagem diversamente aos erros dos demais: não se incomodam; levam na brincadeira; se queixam; se irritam profundamente; discutem; criticam acintosamente, por aí vai. Reflexo também da personalidade de cada um dos membros - cuja identidade está de certa forma protegida pela distância e por um relativo anonimato - os comportamentos individuais nesses encontros são variados.

\footnotetext{
${ }^{5}$ Forma de violência que opera por meio de símbolos, destacadamente a linguagem, e que podem ferir o indivíduo não fisicamente ou corporalmente, mas sua consciência, autoestima, moral, reputação ou prestígio (cf. ELIAS, 1993; ZALUAR e LEAL, 2001).
} 
Comportamentos intolerantes, agressivos e violentos acontecem principalmente em atividades nas quais os grupos são compostos aleatoriamente, misturando jogadores que não se conhecem (virtualmente), inclusive de nacionalidades distintas.

Em caso de jogadores conhecidos, ao invés da cobrança ríspida ou em excesso pode haver, num sentido oposto, uma disposição em ajudar, em auxiliar. Alguns jogadores gostam especialmente disso, de ajudar outros membros e colegas de equipe, principalmente aqueles com baixo desempenho ou inexperientes no jogo. Há aqueles que, em troca talvez apenas do reconhecimento de que são conhecedores profundos do jogo, ou de que são colegas generosos, altruístas, não se negam a repetir inúmeras vezes atividades que não os desafiam técnicataticamente de modo simplesmente a auxiliar outro a "se equipar" melhor. Também prestam uma espécie de consultoria, assessorando outros jogadores a aprimorarem seu desempenho.

Nas raides, para além da competição resultante do enfrentamento direto do oponente controlado pelo computador, que simplesmente executa uma séria de rotinas e ações prescritas pelos programadores, há outro tipo de competição que se estabelece entre os próprios jogadores e que contribui para aumento do estado de tensão-excitação. Não se trata de uma disputa formalizada, direta, com regras explícitas, mas de uma disputa indireta, assentada sobre a performance e a comparação de desempenhos individuais. É um tipo de competição possibilitada especialmente pela acoplagem e utilização de softwares produzidos pela própria comunidade de jogadores (e não pela fabricante do jogo) e que quantificam e comparam numericamente e em tempo real a atuação de cada jogador. Discutirei o principal deles, o Recount, e as implicações de sua utilização.

Seu uso no jogo seria análogo a se, no universo esportivo, os próprios jogadores pudessem ter acesso instantâneo, no decorrer da própria partida, ao registro numérico das ações e desempenhos de cada um dos parceiros da equipe.

\section{RECOUNT: VIGIAR E PUNIR}

O Recount coleta em tempo real os dados relacionados ao combate e os disponibiliza na forma de gráficos, barras e tabelas numa janela à parte, no próprio jogo. Mensura, entre outras coisas, a quantidade de "dano causado" e de "cura realizada" pelos personagens. Seria o equivalente aos scouts das práticas esportivas de alto-desempenho, com a diferença de que no caso do Recount o acesso aos dados é imediato e está disponível aos próprios jogadores (e não a comissão técnica, por exemplo). 
Preocupados com sua própria performance, jogadores mantem um olho no jogo e outro na janela do aplicativo, "esforçando-se para alcançar o topo dos medidores", como notou Nardi (2010, p.58).

A Figura mostra algumas das janelas do aplicativo Recount em funcionamento. A interface da esquerda mostra o dano realizado por cada jogador em uma determinada luta (Ex: Crucix causou $28 \%$ e está em primeiro, ele é o top DPS). Na direita o jogador pode consultar quais habilidades estão sendo mais úteis ou se estão sendo utilizadas na ordem correta conforme prega a teoria.

Figura 1 - Interface do aplicativo Recount e seus recursos mais utilizados

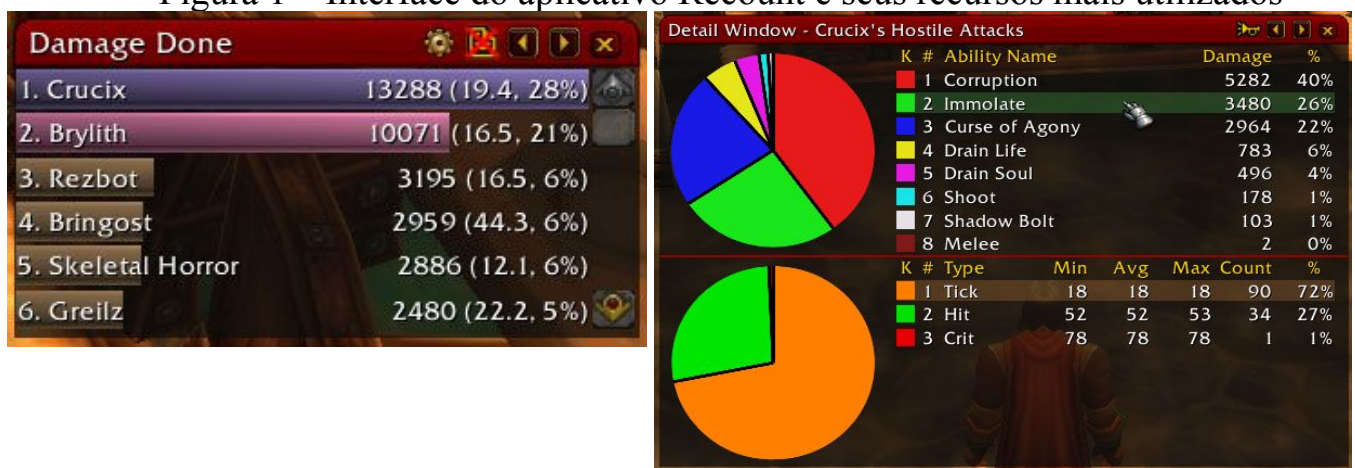

Fonte: https://www.curseforge.com/wow/addons/recount

Ser o "top DPS" na luta, quer dizer, ser o primeiro colocado na lista dos que provocaram mais "dano por segundo", é motivo de orgulho, satisfação. Analogamente, é como se o jogador fosse o "cestinha" no basquete, o "goleador" no futebol, etc.

Por outro lado, se não é frustrante para o jogador figurar abaixo na listagem de desempenho, pode o ser para o restante do grupo. Dependendo da luta e do perfil do grupo, pode existir certa pressão - facilmente convertida em violência simbólica - para que o jogador melhore seu DPS e atinja um mínimo razoável, por exemplo. O grupo pode começar a exigir mais empenho e atenção do jogador, eventualmente manifestando-se via voz ou texto: "tem que aumentar esse dano aí!", “teu DPS está baixo”, “aperta esse dedo aí, rapaz"”.

Às vezes, numa espécie de biópsia virtual, podem inspecionar ${ }^{8}$ os itens que o personagem está vestindo para verificar se ele possui uma qualidade de itens mínima, e se está vestindo os equipamentos da maneira mais eficiente possível, fazendo comentários a respeito.

Se, depois das cobranças e eventuais ajustes, ainda assim ele não atinge uma determinada marca em termos de DPS ou de "cura", o líder do grupo ou os demais jogadores pedem para que o

\footnotetext{
${ }^{6}$ DPS é abreviação nativa para damage per second - dano por segundo.

${ }^{7}$ Cobrança no sentido de que o jogador "apertasse” mais rápida e precisamente os botões, para que fosse mais ágil no combate e melhorasse seu DPS. Equivalente a pedir para um companheiro "correr mais" numa prática esportiva.

${ }^{8}$ Estando próximo de um personagem é possível utilizar o comando "inspecionar" para observar os itens equipados.
} 
jogador se retire. Ou mesmo, numa ação mais violenta, kickam ele (do inglês "to kick", chutar, que no termo nativo significa expulsar à força da partida).

O impacto do Recount na dinâmica do jogo é significativo, a ponto de modificar completamente a maneira como os sujeitos se relacionam durante as atividades. Alguns jogadores percebem a influência que ele exerce e sentem como se o seu uso corrompesse o sentido lúdico do jogo, como ilustrado no trecho a seguir, do depoimento de uma das informantes entrevistadas:

Eu acho que com esse tipo de subsídio [ferramentas como o Recount], o jogo perde sua função. Porque acho que o jogo tem que ser visto como uma forma de lazer. Aonde você vai na hora que você está estressado, quando quer esquecer alguma coisa ou simplesmente desligar do seu dia-a-dia estressante. Aí você vai lá e tem essa porcaria de recount e o povo fala "nossa, você é a última do Recount", "nossa, o seu DPS está muito baixo", sendo que você está ali para rir, para se divertir [...] (Sônia, 31 anos, professora, casada, grávida)

Para kickar alguém basta iniciar uma votação, indicando no espaço correspondente a justificativa para sua expulsão. Se a maioria clicar em "sim”, o jogador é automaticamente expulso daquela luta. Assim, sua utilização por vezes pode ser bastante banal. Pode ocorrer, por exemplo, do jogador ser negativamente surpreendido numa atividade coletiva pelo recebimento de mensagem avisando que foi iniciada uma votação para expulsá-lo. O motivo? Apenas os dizeres: "DPS lixo”. E num instante o jogador está definitivamente "fora da brincadeira".

Não consegui encontrar situações paralelas nos jogos e brincadeiras realizados fora dos ambientes virtuais. Sim, crianças são excluídas das brincadeiras a todo momento e não há quem as reintegre; o "dono da bola" pega seu pertence e vai embora; outro coleguinha se apodera do dinossauro verde se negando a compartilhá-lo, e por aí vai. Mas ainda assim, no conflito offline há certa margem para negociação; na pior das hipóteses, há oportunidade para o revide. No jogo, além de comumente arbitrária e perpetrada quase anonimamente, a expulsão é rápida e definitiva.

Presenciei também diversas ocasiões nas quais jogadores (eu mesmo inclusive) foram kickado sob o argumento de insuficiente desempenho. No fórum oficial do jogo um jogador revela sua indignação quanto à impaciência e intolerância dos jogadores ${ }^{9}$. Depois de relatar um caso que tinha acabo de vivenciar, de maneira irônica ele resume os supostos critérios de expulsão, chamando atenção para sua banalidade:

1) Se vc demora a puxar [atrair os monstros para o combate], vc é kikado [expulso].

2) se vc puxa rápido, vc é kikado.

3) se vc não entende inglês, vc é kikado [...]

4) se vc não tá equipado vc é kikado.

5) se não sabe as lutas, vc é kikado.

${ }^{9}$ Há diversos materiais empíricos com esse teor, mais densamente descritos em Reis e Cavichiolli (2013). 
Num ensaio publicado por um jogador na revista sobre jogos digitais GameSpy, o autor do texto critica a forma como os aplicativos utilitários em geral (especialmente o Recount) “desumanizam” os jogadores, convertendo-os em números. Indignado com a situação por ele vivenciada, na qual narra a expulsão indevida e injusta de um jogador, o autor lamenta dizendo que a cultura desses aplicativos utilitários "garante que esse tipo de porcaria [a expulsão banal de jogadores] ocorra o tempo todo" (JOHNSON, 2012).

Evidentemente, a violência presenciada no interior de certos grupos não é gerada pelo Recount. Antes, são produzidas pelos próprios jogadores, em meio ao calor do jogo. Sem abordar diretamente as condições que identifiquei como propícias à violência no contexto do ciberespaço, o que eu quero mostrar aqui é que ao coletar, compilar e exibir dados referentes ao desempenho de cada personagem, o aplicativo possibilita aos jogadores avaliarem seus pares através de uma informação puramente numérica e racionalizada.

Embora frequente nos esportes coletivos em nível de alta performance, dispositivos semelhantes não são verificados nas atividades esportivas praticadas em outros contextos, onde, para além do indivíduo que monitora variáveis mínimas acerca do próprio desempenho (seu batimento cardíaco e deslocamento, por exemplo) não se vislumbra, ao menos ainda, a utilização de aplicativos ou de especialistas para coleta de dados tal como no alto rendimento.

Assim, nas práticas esportivas lúdicas, não há registros numéricos acerca da partida e do desempenho particular de cada jogador (ex: número de passes errados e a distância percorrida durante uma partida de futebol); os praticantes não podem se avaliar mutuamente por meio de dados objetivos enquanto o próprio jogar acontece. No máximo, a análise fica restrita a uma impressão subjetiva (como quando se diz que alguém está fazendo "corpo mole" na marcação, "errando demais" ou que "não está correndo"). Impressão que pode ser externalizada e discutida coletivamente, mas que não é um número dado, oferecido instantaneamente a todos.

Ao permitir os jogadores compararem diretamente seus desempenhos com base nos números apresentados, o uso de aplicativos dessa natureza acirra a competição dentro das atividades (pelo “top dps”, por exemplo) e também instaura uma severa vigilância: o erro é facilmente identificado e comprovado.

Exemplifico. Numa certa luta de raide, um jogador foi criticado por estar se posicionando de maneira errada ao longo do combate, ficando muito tempo parado em cima de poças que provocavam dano, dificultando enormemente o "trabalho" dos responsáveis pela cura. O jogador criticado se defendeu: “Não, não... Não sou eu que estou fícando em cima das poças não.”. Em seguida, o jogador que tecia a crítica publicou no bate-papo dados comprovando que o jogador 
criticado havia sim recebido dano além do "aceitável". Contra dados do Recount não há argumentos: realmente o jogador estava ficando parado indevidamente em cima das poças - e todos puderam constatar.

É possível pensar no Recount como o panóptico de Foucault (2011, p. 191), quer dizer, como uma tecnologia que instaura um "estado consciente e permanente de visibilidade que assegura o funcionamento automático do poder", fazendo com que "a vigilância seja permanente em seus efeitos". Com o uso do Recount jogadores se encontram atados numa "situação de poder de que eles mesmos são os portadores", submetidos a pressão permanente e constante que "age antes mesmo que as faltas, os erros, os crimes sejam cometidos"10. Seu poder panóptico mantem jogadores num estado de vigilância constante, principalmente sobre si mesmo, instaurando um cuidado permanente no jogar.

Ao que poderia ser questionado: mas o uso do aplicativo não seria opcional, voluntário, a cargo de cada jogador? Não exatamente, pois apesar de sua instalação e uso serem individuais, o uso que se faz dele o torna coletivo. A partir do momento que alguém do grupo esteja usando, os demais sujeitos do grupo já estão sendo monitorados e vigiados, mesmo sem optar por isso. A qualquer momento os dados monitorados podem ser postados no bate-papo coletivo para que todos vejam.

Sônia, a informante já citada, pode não gostar do aplicativo, nem mesmo utilizá-lo, mas há grande chance de existirem outros jogadores utilizando-o. Ela estará sendo monitorada e seu jogar despretensioso, sua despreocupação com o desempenho, poderá contrastar com outras formas de jogar, inclusive aquelas excessivamente voltadas ao desempenho. O poder invisível e onipresente do Recount, "capaz de tornar tudo visível” e quantificável, especialmente aquilo que o jogador não "vê" e nem é capaz de processar tão rápida e eficazmente, alcança até aqueles que não escolher usar a ferramenta. Seu poder panóptico faz com que os jogadores se comportem como se estivessem sendo observados, independentemente de essa observação estar sendo efetivamente realizada ou não, tal como os detentos na prisão panóptica de Foucault.

Mas o fato é que, apesar dos inconvenientes de sua utilização, e da violência perpetrada com respaldo das informações por ele colhidas e apresentadas, o Recount é indispensável à dinâmica social já instituída no jogo. O jogador que deseja raidar se preocupa ou deverá se preocupar, inevitavelmente, com sua performance no jogo. E o Recount, nesse caso, é utilizado como o

\footnotetext{
${ }^{10}$ Foucault fala dos detentos na prisão idealizada por Benthan no século XVIII mas numa analogia geral à sociedade disciplinar. Na metáfora foucaultiana, o panóptico representaria a "extensão progressiva dos dispositivos de disciplina ao longo dos séculos XVII e XVIII [e] sua multiplicação por meio de todo o corpo social" (FOUCAULT, 2011, p. 198). As citações extraídas, contudo, se aplicam interessantemente a situação de uso do Recount.
} 
principal indicador. É através dele, vendo os números subirem, vendo seu personagem galgar posições nas listas de quem curou mais, de quem provocou mais dano, que o jogador percebe mais diretamente sua melhora, ou melhor, contabiliza-a, comprova-a quantitativamente. Constatar essa evolução, esse desenvolvimento é também prazeroso para o jogador.

\section{DIFERENTES SENTIDOS E SIGNIFICADOS}

Outra questão relacionada às tensões e erupções de violência no contexto do jogo está associada ao fato da existir uma diversidade de interesses e expectativas em relação a certas atividades do jogo sem que haja espaço, tempo e possibilidade para uma efetiva negociação destas. O que se observa é que os diferentes sentidos e significados atribuídos pelos jogadores dificilmente se constituem em diferentes maneiras de se jogar, pois uma dinâmica social fortemente estabelecida no contexto do jogo institui formas hegemônicas de jogar, orientando e moldando determinantemente as maneiras de usufruir do jogo (em direção à performance e à competitividade).

A tensão efetivamente surge porque não há dentro da dinâmica posta como conciliar as diferentes expectativas e sentidos atribuídos à prática com a forma dominante de jogar. Além da diversidade de interesse, acrescenta-se à situação o fato de que em muitas das partidas os grupos são formados por jogadores que não se conhecem pois foram agrupados automaticamente por uma ferramenta próprio do jogo, podendo inclusive não falar o mesmo idioma (o que dificultaria bastante uma eventual negociação dos interesses se possível fosse, por exemplo), coincidentemente podem até terem jogado juntos outras partidas, mas dada a alta rotatividade e circularidade de jogadores, dificilmente tomariam ciência disso, nem o fariam futuramente, caso viessem fortuitamente a cruzar-se novamente.

Também não há estratificação e distribuição dos sujeitos por nível de desempenho e habilidade, o que faz com que se misturem nas mesmas atividades jogadores com níveis muito discrepantes. Mas isso também não se aplicaria às atividades esportivas? Sim, porém em níveis de amplitude diferentes e com possibilidade maior de negociação. Explico.

Sabe-se que o conceito de esporte é polissêmico (BETTI, 1998) e que praticantes de modalidades esportivas atribuem diferentes sentidos e significados à mesma prática, o que pode ser facilmente observado através de suas diversas manifestações no cotidiano (vulgarmente simplificadas como esporte de lazer, de alto-rendimento, de saúde, educacional, etc.). Além da diversidade de sentidos e significados atribuídos a uma dada prática esportiva, sabe-se também da existência de uma heterogeneidade de sentidos e significados dentro de um mesmo grupo ${ }^{11}$, isto é, 
entre os indivíduos que estão dentro do círculo mágico (HUIZINGA, 2008) compartilhando a mesma prática no mesmo exato momento. Também é possível perceber que os praticantes e adeptos possuem competências, capacidades e níveis de habilidades diferenciados. Até aqui tudo bem, jogos esportivos e o WOW seriam semelhantes.

A principal diferença com relação a esse quesito, no entanto, é que nas atividades esportivas há, em comparação, uma maior ou efetiva possibilidade de negociação da heterogeneidade, pois apesar dos interesses relativamente heterogêneos de cada indivíduo, o grupo se consolida em torno de uma referência mais ou menos homogênea de como o jogo se desenrola ou deve se desenrolar (mais "pegado", menos acirrado, etc.). Há uma negociação constante dos diversos interesses e expectativas dos jogadores e ajustes são necessários e realizados a todo momento. $\mathrm{O}$ que não quer dizer que isso seja feito de forma completamente democrática, sem tensão, ou de maneira aberta e explícita - o que aparece bem analisado em Stigger (2005), por exemplo.

O fato é que o sujeito negocia com o grupo (não necessariamente de forma explícita ou declarada) e consigo mesmo sua forma e intensidade de participação a depender de suas expectativas, vontades, condições físicas, etc. Assim, depois de experimentar ou vivenciar por um tempo atividades com um grupo, participantes que não se sentiram (ou não se sentem) contemplados, satisfeitos com a dinâmica colocada podem negociar mudanças ou buscar outros lugares, pessoas ou grupos que lhe permitam atender seus interesses, ou mesmo manter atividades paralelas, tendo consciência de que as dinâmicas estabelecidas são diferentes em cada lugar. De qualquer maneira, num processo mais ou menos demorado, mais ou menos tenso, o grupo tentará equilibrar os diferentes interesses para que o jogo mantenha um nível de tensão ótimo (ELIAS, DUNNING, 1992), isto é, um nível de competição e sociabilidade adequado às expectativas criadas.

Ademais, é importante frisar que geralmente indivíduos não aparece para participar de uma prática esportiva sem ter uma referência mínima sobre o aparente significado que o grupo de praticantes atribui a ela, que, por exemplo, pode ser obtida por um conhecido que o convida a jogar ou por uma mesma que superficial observação anterior. Em todo caso, no contexto esportivo os indivíduos não "aparecem" dentro da partida - como literalmente e frequentemente ocorre no $\mathrm{WOW}^{12}$ e em outros jogos multiplayers.

\footnotetext{
${ }^{11}$ Como evidencia claramente análises produzidas a partir de experiências etnográficas que envolvem o contato imersivo com grupos de práticas esportivas, como é o caso de pesquisas como Silveira (2008) e Stigger (2005), por exemplo. Stigger (2005, p.248), mostra que "grupos distintos são capazes de desenvolver maneiras específicas de praticar o esporte, [e que] também no âmbito interno destes grupos parece possível coexistirem formas diferenciadas de indivíduos particulares apropriarem-se desta prática social".

${ }^{12}$ Refiro-me a ferramenta do jogo que agrupa aleatoriamente (de vários servidores, de vários países) jogadores que sinalizam interesse em participar de uma dada atividade.
} 
No WOW, além da diversidade de sentidos e significados atribuídos pelos jogadores que “aparecem” subitamente em jogo (e "desaparecem" ao seu final), a discrepância em termos do nível de desempenho (jogadores muito habilidosos, misturados com pouco habilidosos) afetam demasiadamente as partidas, gerando as já conhecidas tensões. Embora a discrepância em termos de nível de desempenho seja evidente também nos jogos esportivos (comparando-se profissionais e iniciantes, por exemplo), a lógica como se estratifica a competição e a formação de grupos de interesse (em categorias de idade, de tempo de treinamento, de esfera de abrangência - local, regional, colegas de escola, etc.) parece não fazer disso um problema já que a possibilidade de transitar por entre esses grupos e esferas é limitada, reduzida (devido a questões de mobilidades, sociabilidade e restrições de ordem técnica e simbólica).

Já nas atividades do WOW não. A discrepância nos níveis de desempenho dentro de uma atividade é muito maior, e o mais complicador: sem os sujeitos optarem deliberadamente por isso (por jogar com alguém que possui um desempenho muito superior ou inferior).

O tumulto é mais facilmente visualizado se, em analogia com uma dada prática esportiva, imaginássemos um populoso cumbucão ${ }^{13}$, mas que contasse não com dezenas e sim com milhares de participantes, com variações em termos de idade, nível de habilidade futebolística, condição física e dispondo de diferentes interesse e expectativas, etc.

Na era da globalização e da rápida circulação da informação através da internet, favorecendo o relacionamento e o agrupamento de pessoas sócio e culturalmente distantes em torno de uma mesma prática de lazer, WOW representa a faca de dois gumes desse processo. Tem o potencial de reunir fácil e rapidamente pessoas com interesses comuns mas, paradoxalmente, distintos. Ao mesmo tempo em que agrupa jogadores interessadas no mesmo jogo, também agrupa jogadores com preferências e gostos muito distintos em relação ao como jogar. Nem todos encontram seu espaço nessa turba virtual.

\section{CONSIDERAÇÕES FINAIS}

\footnotetext{
${ }^{13}$ Sistema para montagem de equipes onde os nomes dos participantes são colocados em um recipiente (cumbuca) para sorteio.
} 
As raides explicam apenas uma parte do que é jogar WOW. Todavia, a dinâmica presente nessa atividade impulsiona outras atividades no jogo e possivelmente está presente em outros jogos do gênero.

No universo virtual do jogo as relações não são necessariamente harmônicas e nem sempre a interação se dá de forma amistosa, cordial ou pacífica. Cobranças acintosas, xingamentos, comentários depreciativos são frequentemente observados. É digno de nota o súbito trânsito entre situações de sociabilidade e de conflito, eventualmente descambando em episódios de intensa violência simbólica.

Embora os apontamentos tenham tomado o WOW como base empírica, observações encontradas em pesquisas sobre outros jogos do gênero MMORPGs (e que não caberia citar aqui) me levam a considerar que as problemáticas centrais aqui levantadas (da violência simbólica, do uso de dispositivos para quantificação e racionalização do desempenho, do agrupamento de sujeitos desconhecidos com diferentes interesses e expectativas) possivelmente não é restrito ao universo do jogo estudado.

Se, nos termos aqui apresentados, a prática do WOW é até certo ponto parecida com a prática de uma atividade esportiva - a despeito da ausência da amplitude de movimento humano tradicionalmente característico das atividades dessa natureza - entendo que mais importante do que buscar qualquer tipo de enquadramento é tentar verificar o quanto é possível aprender com qualquer uma dessas atividades para melhor interpretar, do ponto de vista acadêmico, a outra.

\section{REFERÊNCIAS}

BETTI, Mauro. A janela de vidro: esporte, televisão e Educação Física. Campinas, Papirus, 1998.

ELIAS, Norbert; DUNNING, Eric. A busca da excitação: desporto e lazer no processo civilizacional. Trad. Maria Manuela Almeida e Silva. Lisboa: Difel, 1992.

ELIAS, Norbert. O processo civilizador. Trad. Ruy Jungman. Rio de Janeiro: Zahar, 1993, v.2.

FOUCAULT, Michel. Vigiar e punir: nascimento da prisão. Petrópolis: Vozes, 2011.

GONZÁLEZ, Fernando Jaime; FRAGA, Alex Branco. Afazeres da educação física na escola: planejar, ensinar, partilhar. Erechim/RS: Edelbra, 2012.

GONZÁLEZ, Fernando Jaime; BRACHT, Valter. Metodologia do ensino dos esportes coletivos. Vitória: UFES, Núcleo de Educação Aberta e a Distância, 2012.

HUIZINGA, Johan. Homo Ludens: o jogo como elemento da cultura. São Paulo: Perspectiva, 2008. 
JOHNSON, Leif. Massivity: How UI Mods Burn MMORPGs. In.: Revista GameSpy. Disponível em: http://pc.gamespy.com/pc/world-of-warcraft-mists-of-pandaria/1226350p1.html. 2012. Acesso em 04 set. 2021.

NARDI, Bonnie. My life as a Night Elf Priest: an anthropological account of World of Warcraft. Michigan: The University of Michigan Press, 2010.

REIS, Leoncio José de Almeida. Tese (Doutorado em Educação Física) - Universidade Federal do Paraná. 2013.

SILVEIRA, Raquel da. Esporte, homossexualidade e amizade: estudo etnográfico sobre o associativismo no futsal feminino. Dissertação (mestrado em Ciências do Movimento Humano) UFRGS. Porto Alegre, 2008.

STIGGER, Marco Paulo. Educação física esporte e diversidade. Campinas, SP: Autores Associados, 2005.

ZALUAR, Alba; LEAL, Maria Cristina. Violência extra e intramuros. In: Revista Brasileira de Ciências Sociais. v.16 n.45 p.145-164. fev. 2001.

\section{NOTAS DE AUTOR}

\section{AGRADECIMENTO}

Não se aplica

\section{CONTRIBUIÇÃO DE AUTORIA}

Não se aplica

\section{FINANCIAMENTO}

Não se aplica.

\section{CONSENTIMENTO DE USO DE IMAGEM}

Não se aplica.

\section{APROVAÇÃO DE COMITÊ DE ÉTICA EM PESQUISA}

Aprovado pelo Comitê de Ética do Setor de Ciências da Saúde da UFPR (n. 84028, aprovado em 28/08/2012).

\section{CONFLITO DE INTERESSES}

Não há conflito de interesses.

\section{LICENÇA DE USO}

Os autores cedem à Motrivivência - ISSN 2175-8042 os direitos exclusivos de primeira publicação, com o trabalho simultaneamente licenciado sob a Licença Creative Commons 
Attribution Non-Comercial ShareAlike (CC BY-NC SA) 4.0 International. Esta licença permite que terceiros remixem, adaptem e criem a partir do trabalho publicado, desde que para fins não comerciais, atribuindo o devido crédito de autoria e publicação inicial neste periódico desde que adotem a mesma licença, compartilhar igual. Os autores têm autorização para assumir contratos adicionais separadamente, para distribuição não exclusiva da versão do trabalho publicada neste periódico (ex.: publicar em repositório institucional, em site pessoal, publicar uma tradução, ou como capítulo de livro), com reconhecimento de autoria e publicação inicial neste periódico, desde que para fins não comerciais e compartilhar com a mesma licença.

\section{PUBLISHER}

Universidade Federal de Santa Catarina. Programa de Pós-Graduação em Educação Física. LaboMídia - Laboratório e Observatório da Mídia Esportiva. Publicado no Portal de Periódicos UFSC. As ideias expressadas neste artigo são de responsabilidade de seus autores, não representando, necessariamente, a opinião dos editores ou da universidade.

\section{EDITORES}

Mauricio Roberto da Silva, Giovani De Lorenzi Pires, Rogério Santos Pereira.

\section{EDITOR DE SEÇÃO}

Juliano Silveira

\section{REVISÃO DO MANUSCRITO E METADADOS}

João Caetano Prates Rocha; Keli Barreto Santos, Juliana Rosário.

\section{HISTÓRICO}

Recebido em: 04 setembro 2021

Aprovado em: 22 novembro 2021 